\title{
Development of Metallic Coil Identification System based on RFID
}

\author{
Myunsik Kim ${ }^{1}$, Beobsung Song ${ }^{2}$, Daegeun Ju², \\ Eunjung $\mathrm{Choi}^{2}$, and Byunglok $\mathrm{Cho}^{2}$ \\ ${ }^{1}$ Sogang Institute of Advanced Technology(SIAT), Sogang Univ. \\ ${ }^{2}$ Ubiquitous Gwangyang \& Global IT Institute, \\ Republic of Korea
}

\section{Introduction}

Recently, RFW gains increasing attention, since RF signal can eliminates the need an optical line of sight and transmits relatively large amount of information from several tens of tags in real time (Finkenzeller, 2003) (Landt. 2001). Based on these advantages, RFID is applied in various fields. For example, RFID is widely spreading on products identification in logistics and distribution fields instead of barcode (Chawla \& Ha, 2007). The bus card and RF pass are famous applications of RFID. Also, the development of special tags such as metallic tag widens the applicable fields of RFID (Nikitin \& Rao, 2006) (Kim et al, 2005). Among the RFID applications, this paper focuses on the RFID technique for the SCM (Supply Chain Management) regarding an iron and steel industry. Specially, the RFID based steel coil identification system during a crane operation is developed. Since the iron and steel industry is key industry providing material to other industries, it has no small effect.

The system is developed for two purposes as follows. Nowadays, many factories employ sophisticated machinery that automates many kinds of process. However, some processes such as the quality checking, packaging, loading / unloading products to freight vehicle, and so on are still dependent upon the workers, who encounters danger under the automated system. The more the industrial field becomes automated, the more the field is dangerous. Thus, the developed system ensures safety of workers by releasing them from the products identification and checking checking process. Also, the automated product identification system improves the efficiency of the manufacturing and distribution process by preventing missing or mixing of products.

One of technical challenges associated with the RFID based coil identification is to apply the system to the existed automated system while sustaining the identification performance easily affected by environmental conditions such as reflection, refraction, and scattering of RF signal from metallic surface of coils, crane and equipments. To cope with the problem, two key techniques are proposed in this paper. First, the effective tag attachment method is proposed considering the shape and properties of metallic coils, and working environment. Second, robust reader antenna system is proposed to identify tag attached inside coil efficiently. An antenna case is developed to reduce the effect from the attached surface and improve tag identification performance by control beam pattern of the antenna.

Source: Radio Frequency Identification Fundamentals and Applications, Design Methods and Solutions, Book edited by: Cristina Turcu, ISBN 978-953-7619-72-5, pp. 324, February 2010, INTECH, Croatia, downloaded from SCIYO.COM 
To verify validity of the proposed system, simulation is performed using MWS 2008 EM simulator and test using various model coils in laboratory. The experimental results in real industrial environment in POSCO show that The coil is identified very successfully using the proposed system.

This paper is organized as follows. In chapter II, the necessity of metallic coil identification system in POSCO and first development is described. Experiment results using the developed system and its problems are shown in Chapter III. Chapter IV shows the further improvement of the RFID system and its simulation and experimental results are shown in Chapter V. Finally, conclusions are drawn in chapter VI.

\section{RFID based coil identification system}

\subsection{Background of the research}

In POSCO, the products such as metallic coil are packaged and banded after manufactured and stored until delivered to customer. Since the coil is heavy over several tons, cranes are used to move the coil as showing in Fig. 1. The crane is automated then it is important to manage the coil information correctly while it is moved. Currently, the coil Information is managed using the stored position in warehouse. In general, the information is correct, however, if there is error in the coil manufacturing schedule or sensed location of the crane, coils are lost or mixed. Thus, sometimes, wrong coil is delivered to customers, it cause problem in time, cost, and credit.

For the problem, a barcode label with product code, size, weight and etc is attached to a coil and workers check the information periodically. The barcode is printed tag with several vertical lines. In order to read the barcode, workers should come close and align reader and barcode for scanning the lines with laser light. It spends much time to read barcode one by one. Also, the printed barcode is easily stained or injured, it prevent from reading the stored data in the barcode.

For the problem, the RFID based coil identification system is proposed. An RF tag is attached to coil, which is identified using reader antenna installed to the crane and the information is transferred to MES (Manufacturing Execution System) server. Even though the coil storing map information is incorrect, it is fixed automatically when crane picks up the coil without any effort of workers.

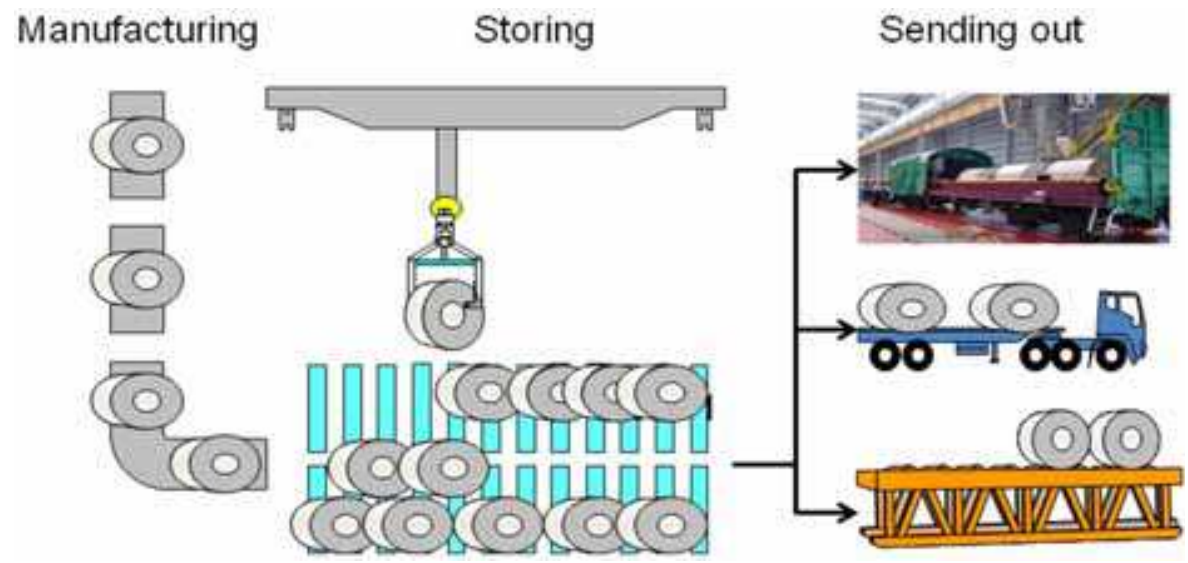

Fig. 1. The management of coil after manufacturing 


\subsection{Overview of developed system}

Fig. 2 shows the overview of proposed system. RF tag is attached to inside of a coil, which is identified using reader antenna installed to crane shoe. The identified information is transmitted to MES server through TCP/ IP interface then the real time sensing and tracking of a coil under the crane operation is available.

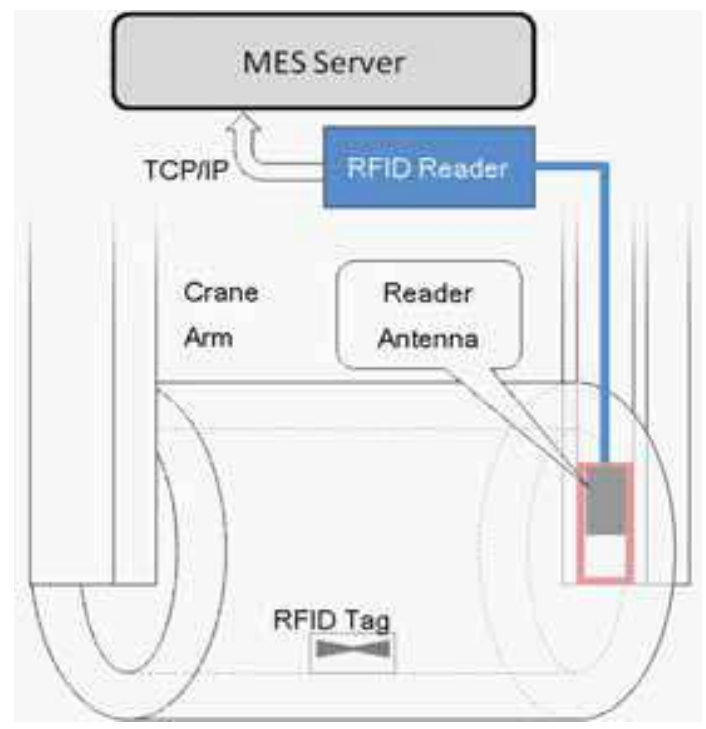

Fig. 2. Overview of developed system

However, since the coil and the neighboring equipments including crane are metallic object, the identification performance of the RFID system is lowered affected by the environmental effect. Also, in order to install the developed system in existing automated system without any changes, the system should be satisfy the conditions as follows.

1. The identification performance should be unchanged under the environment conditions surrounded by metallic object such as coil, crane, and other equipments.

2. The reader should read target tag only among neighboring tags.

3. The system is possible to be installed to current crane without any changes.

4. The tag should be cheap and light.

RFID system used in the developed system is shown in table 1. More detailed is described in following section.

\begin{tabular}{|c|c|}
\hline Tag & UPM raflatac Dogbone Type \\
\hline Reader & Alien ALR-9900 reader \\
\hline Reader Antenna & Ceramic Patch Antenna \\
\hline Interface to MES & TCP/ IP \\
\hline Tag on metallic surface & Flag tag technique \\
\hline
\end{tabular}

Table 1. RFID system applying in the developed system 


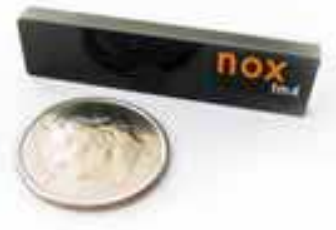

(a) Nox-TM4 Metal Tag SimplyRFW Corp.

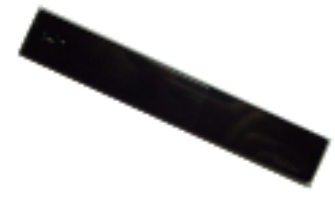

(b) P0106AT Metal Tag Sontec Inc

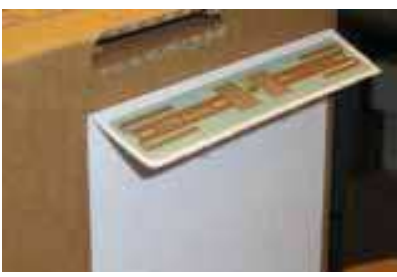

(c) Flag Tag

UPM Raflatac

Fig. 3. UHF RFID tag for metallic surface

\subsection{Tag on metallic surface}

Fig. 3 shows the tags can be used on metallic surface. Fig. (a) and (b) show metal tag, special tag that can be read, even though it is attached on metallic surface. Tag antenna is printed on a ferroelectric material such as ceramic with thickness of several millimeters. The basic principle of the metal tag is shown in Fig. 4. Wireless communication of RFID becomes possible by electromagnetic flux penetrating between two antennas of reader and tag as shown in Fig. 4-(a). However, when a metal is close to tag antenna, eddy current caused by reader's magnetic field is generated and it cancels the magnetic field necessary for communication as shown in Fig. 4-(b). When ferroelectric material is inserted between tag antenna and metal surface as shown in Fig. 4-(c), the material concentrates magnetic flux then the flux can flows without loss (Kim et al, 2005). Then the communication distance is improved as results. However, the price of the metal tag is much expensive than ordinary tag printed on film such as PI. Also, the metal tag is heavy then it comes off from the attached surface by vibration more easy comparing with ordinary tag while a tag attached object is moved. The cost and weight of the metal tag is chief obstacle to be applied.

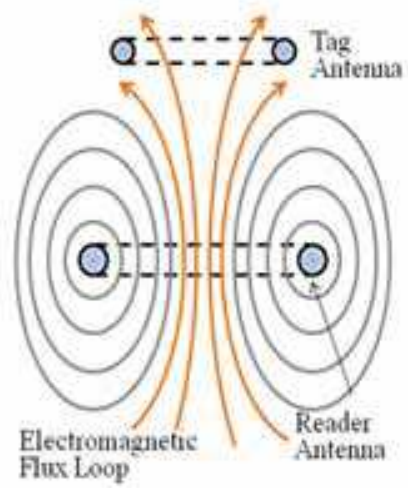

(a) Normal Communication Condition

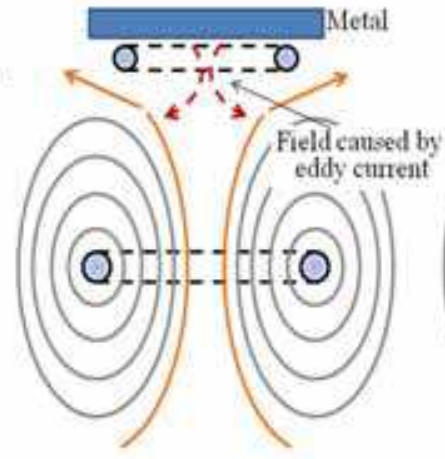

(b) Communication condition with a metal surface in a vicinity

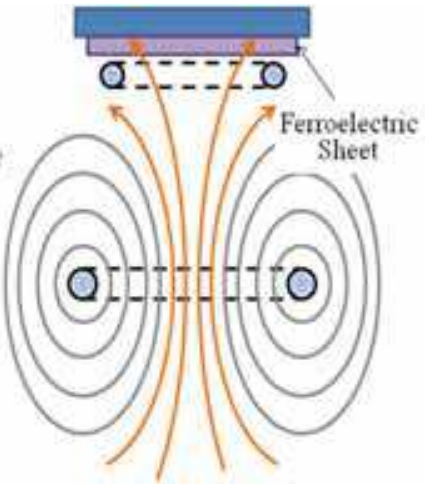

(c) Communication Condition with ferroelectric sheet present

Fig. 4. Basic principle of metal tag 
Thus, the flagtag technique proposed by UPM is used in the developed system (Victor et al, 2006). Note that there is enough space between tag antenna and attached surface, the RF communication is available. Flagtag technique is very simple idea that makes space between tag and attaching surface. Fig 3-(c) shows the flagtag using label sticker. A tag is inserted in label and the tag is stood by folding the label as shown in the figure. Since general cheap film type tag can be used attaching on surface of various materials such as metal, paper, and so on with the flagtag technique, it has advantage in cost and applicability.
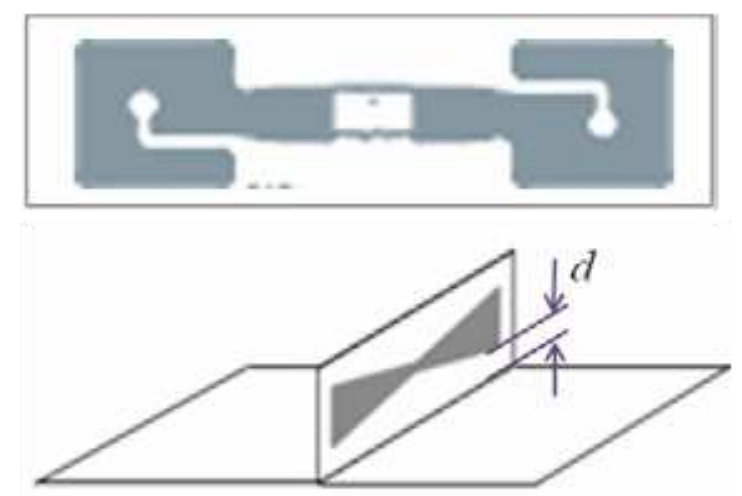

Fig. 5. Tag used in the system

Fig. 5 shows the tag used in the developed system. A UPM dogbone type UHF ranged RFID tag sized of $93 \times 23 \mathrm{~mm}$ is used in paper label. The tag is erected by folding the paper label as shown in lower of Fig. 5. When the tag is attached, the identification performance is varied according to the distance $d$ between the tag and the attached surface. Fig. 6 shows the strength of $\mathrm{RF}$ signal transmitted from the tag varied according to the distance $d$. As shown in the figure, the strength is almost same with normal condition when the distance is over $2 \mathrm{~cm}$.

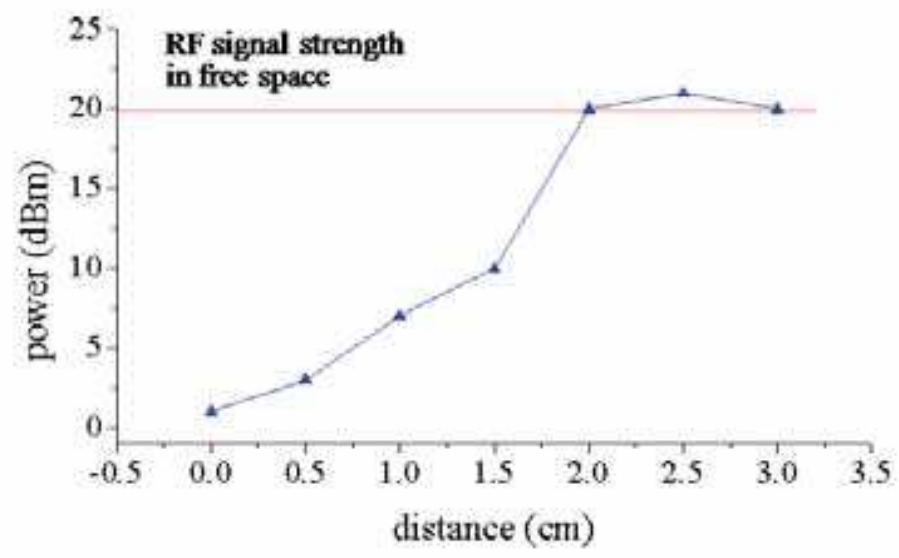

Fig. 6. Power of transmitted RF signal according to the distance $d$ 


\subsection{RFID reader and antenna}

ALR-9900 UHF RFID reader of Alien technology corp. is used in the developed system. In order to install reader in current crane, the smaller reader is better. Also, two more antenna port is required to install antennas to two crane shoe of a crane. Since the MES server is far from crane and it is hard to use wireless communication in factory environment, TCP/ $\mathrm{P}$ communication interface is required to transmit data without any loss. Table 2 shows the reader that can satisfy the above conditions.

\begin{tabular}{|c|c|c|}
\hline Name & ALR-9900 & SRU-FK0100 \\
\hline Photo & Elien Technology Corp. & Samsung Techwin \\
\hline Manufacturer & EPC Gen2 & EPC Gen2 \\
\hline Tag Protocol & ISO18000-6c & ISO18000-6(TypeB) \\
\hline Frequency & $902.75 ~ 927.25 \mathrm{MHz}$ & $910-914 \mathrm{MHz}$ \\
\hline Size & $190 \times 160 \times 40 \mathrm{~mm}$ & $140 \times 110 \times 26 \mathrm{~mm}$ \\
\hline Antenna Ports & 4 Ports & 4 Ports \\
\hline I/ F & RS-232, TCP/ IP & RS-232, TCP/ IP \\
\hline
\end{tabular}

Table 2. Specification of RFID readers

The specification of two readers is similar. Comparing with the Alien reader, SRU-FK0100 of Samsung Techwin has an advantage in size. However, the SRU-FK0100 reader affect to another sensor installed in crane then causes error in crane operation. After install the reader to crane and attach two antennas to crane shoe, the operation of folding and unfolding the shoe becomes unavailable. There is no reason to make the phenomena, since all sensors in the crane are shielded and the reader satisfies the standard of RFW reader specification.

Fig. 7 shows the noise transmitted from the antenna port of the two RFID readers. The noise level of two reader is under the standard. However, as shown in the figure, SRU-FK0100 reader has more noise than the ALR-9900 reader. It is regards as the reason that causes the crane to malfunction. Since the industrial field with many sensors for automation can be easily affected by any kinds of RF signal, the reader with less noise is better.

A Ceramic patch antenna sized of $\square 80 \mathrm{~mm} \times 7 \mathrm{~mm}$ is used with the ALR-9900 reader. Fig. 8 shows the antenna attached to crane shoe. Since the available width of the crane shoe is 12 $\mathrm{cm}$ only, the antenna is determined considering the required space for packaging. The antenna has gain of $2 \sim 2.5 \mathrm{dBi}$ and can detect a tag of $6 \mathrm{~m}$ aw ay with the ALR-9900 reader. To check the identification performance in real environment, we perform test in POSCO. Detailed experimental results are shown in following section. 
909.5 910MHz
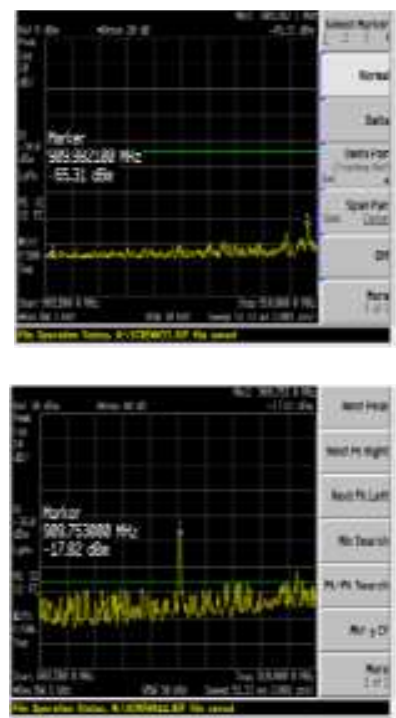

914 914.5 MHz

ALR-9900

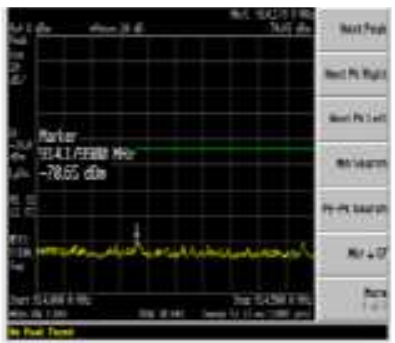

SRU-FK0100

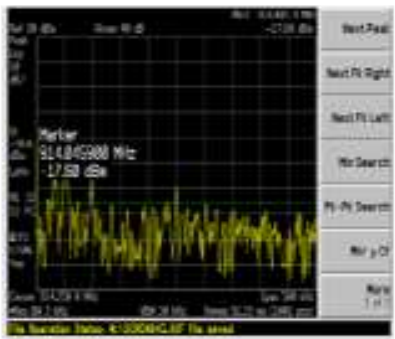

914.5 1000 MHz
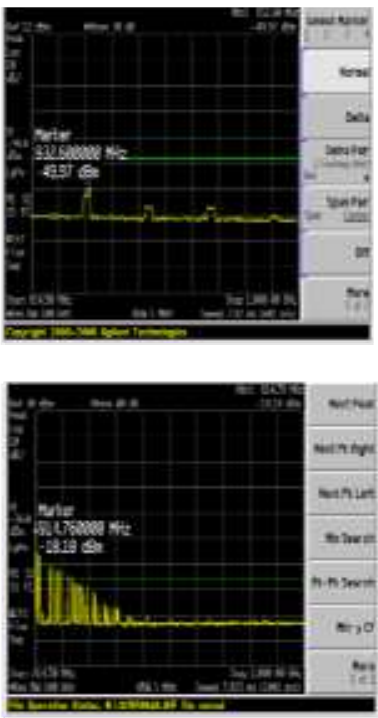

Fig. 7. Noise according to various frequency range
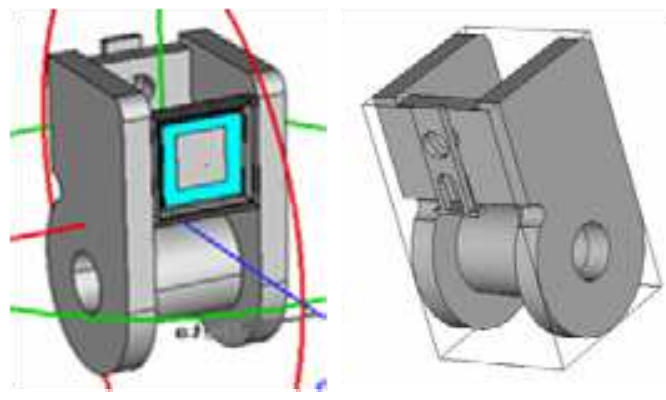

Fig. 8. Reader antenna attached to crane shoe

\section{Experiment results}

Fig. 9 shows the tag and antenna attached to coil and crane shoe. Label with tag is folded and attach inside of the coil parallel to the coil plane. In order to avoid damage, the label is put on $50 \mathrm{~cm}$ inner from the coil plane. Reader antenna is protected by plastic package and attached to crane shoe as shown in the figure. Fig. 10 shows the coil identification process when crane picks up the coil.

When the crane arm is down to pick up target coil, the tag inside the coil is identified using the antenna in the crane shoe. The identified information is transmitted to MES server and compared with the coil information in the storing map. If the two information are same, the crane lifts up the coil. Table 3 shows the experimental results using the developed system. 


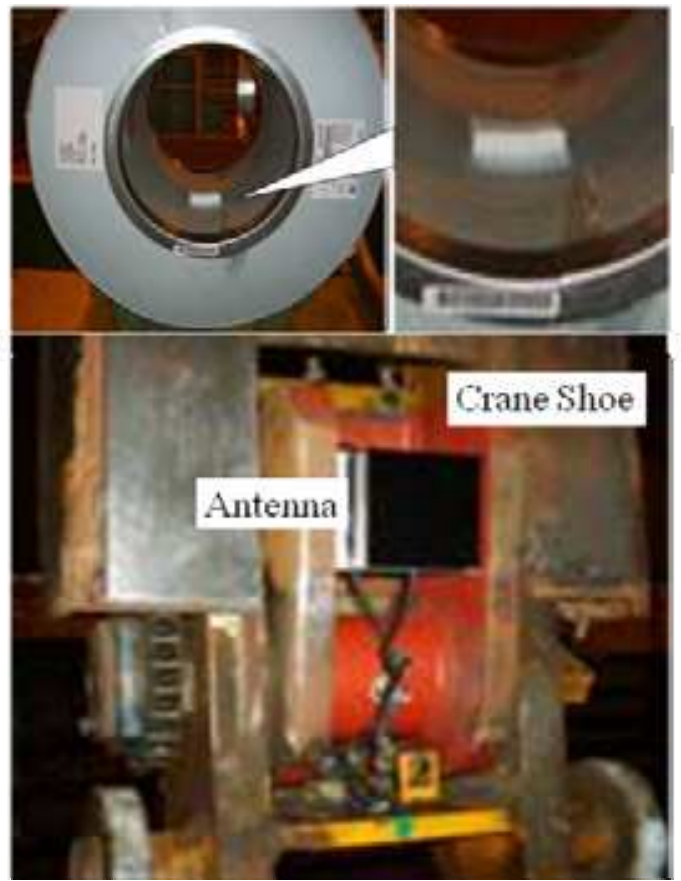

Fig. 9. (upper) Tag attached inside of coil, (lower) Antenna attached on crane shoe

(a)

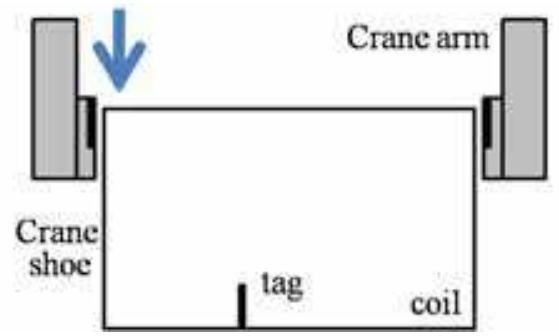

(c)

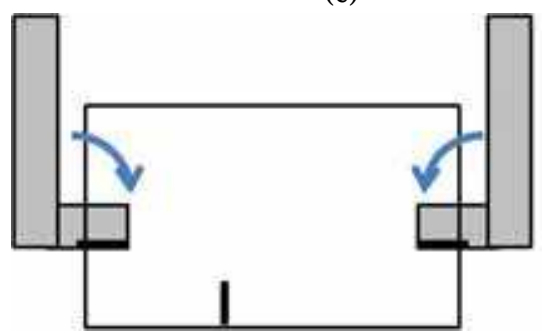

(b)

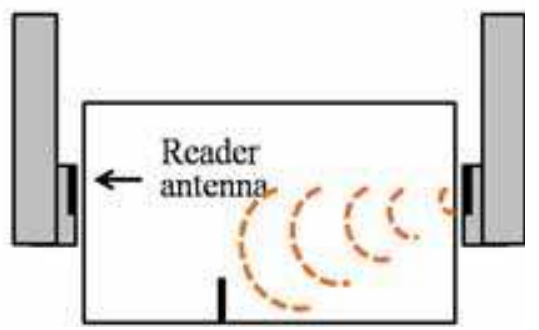

(d)

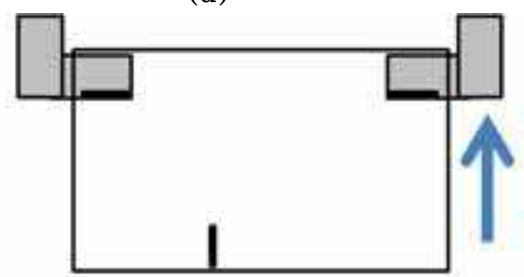

Fig. 10. Coil identification process using developed system while crane operation

(a) Crane arm is down to pick up target coil (b) Tag is identified,

(c) Unfolding crane shoe, (d) Lift up the coil 


\begin{tabular}{|c|c|c|c|c|c|}
\hline \multicolumn{2}{|c|}{ Day } & 1 st & 3rd & 5 th & 7 th \\
\hline \multicolumn{2}{|c|}{ No. of Manufactured Coils with tag } & 440 & 429 & 511 & 505 \\
\hline \multirow{2}{*}{ Error } & Identify wrong coil & 4 & 9 & 9 & 6 \\
\cline { 2 - 6 } & Missing & 1 & 5 & 16 & 40 \\
\hline \multicolumn{2}{|c|}{ Error rate (\%) } & 1.1 & 3.3 & 4.9 & 9.1 \\
\hline
\end{tabular}

Table 3. Test result of coil identification

Tags issued following the production schedule is attached to a coil during packaging process and the coil is moved to warehouse using crane. Three cranes are selected for the test such as crane used for moving coils to warehouse, and in warehouse and to freight vehicle for shipment.

To test with as many tag attaced coils in the warehouse as possible, the test is performed during a week. As shown in the results, the fail rate increases. It is caused by the increasing the neighboring tags in the warehouse. First day, there are tags issued in the day then the reader can identify the target tag only. However, the error rate increases in $3 d$ day. The tag behind the antenna is read by the back-radiation of RF signal. To solve the problem, we reduce the $\mathrm{RF}$ signal transmission power. It is resulted that the missing rate increases. When the power increases, the neighboring tags are detected together, and power decreases, the reader can not detect the target tag. Also, the tag is attached parallel to the coil plane, the tag lies down by the distortion caused by the effect of the curved surface of the coil. As the tag comes close to metallic surface of the coil, the identification performance is lowered, then the identification fail rate increases. For the problem, the developed system is improved in two directions. It is shown in following section.

\section{Improvement of developed RFID based coil identification system.}

In this paper, the developed RFID based coil identification system is improved in two directions: change of the tag attaching method and development of reader antenna package to control the beam pattern of RF signal transmitted from the antenna.

\subsection{Tag attachment method.}

First, the tag attachment method is changed. Fig. 11-(a) shows the previous method that the tag is attached parallel to the coil plane. In the case, since the lower paer of the label is straight, the tag is distorted by the curved surface of the coil. This problem can be solved by making the lower part of the tag curve fitted with the coil. However, the tag attachment process becomes complicated and the label should be made in various shapes according to the coil size. In addition, since the size of the tag shown in the coil plane is maximized with the attachment method, the tag is easily broken during the banding process and effect of wind passing through the coil.

For the problem, the tag attachment method is changed to be perpendicular to the coil plane as shown in Fig. 11-(b). The tag attachment surface is not curved and only the side of the tag is shown from the coil plane then the problem of distortion and damage of the tag can be minimized. However, when the tag is attached following the coil direction, the tag is at right angles with the reader antenna. Note that the $\mathrm{RF}$ signal transmitted from reader antenna to tag 
is maximized, when the reader antenna and tag is parallel (Stutzman \& Thiele, 1999). Fig. 12 shows the power of the transmitted RF signal from reader antenna to tag according to the angle between them. Y-axis of the graph is the strength of transmitted RF signal to the tag from the reader antenna set $30 \mathrm{~cm}$ upper position of the tag reflecting the crane shoe position and the coil. The reader antenna send RF signal of $30 \mathrm{dBm}$. X-axis shows tag attached position from the reader antenna plane. The tag is attached at 20 and $50 \mathrm{~cm}$, respectively. The results clearly show that the strength is lowered when the tag and reader antenna is perpendicular.

(a)

(b)

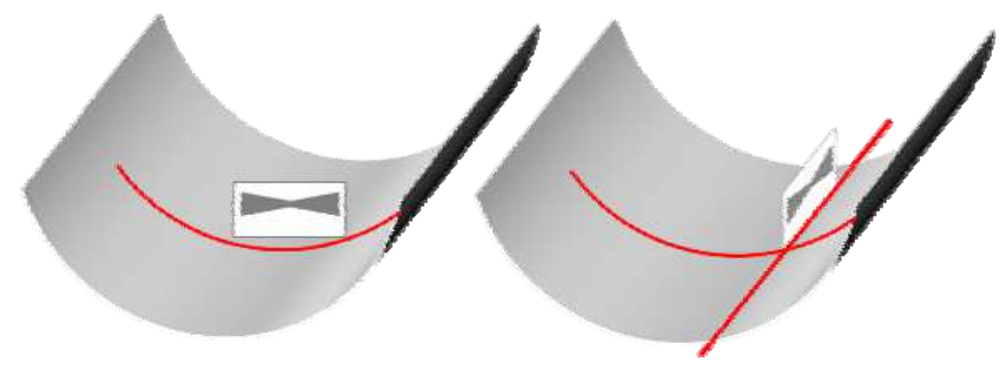

Fig. 11. Tag is attached (a) parallel to coil plane, (b) perpendicular to coil plan.

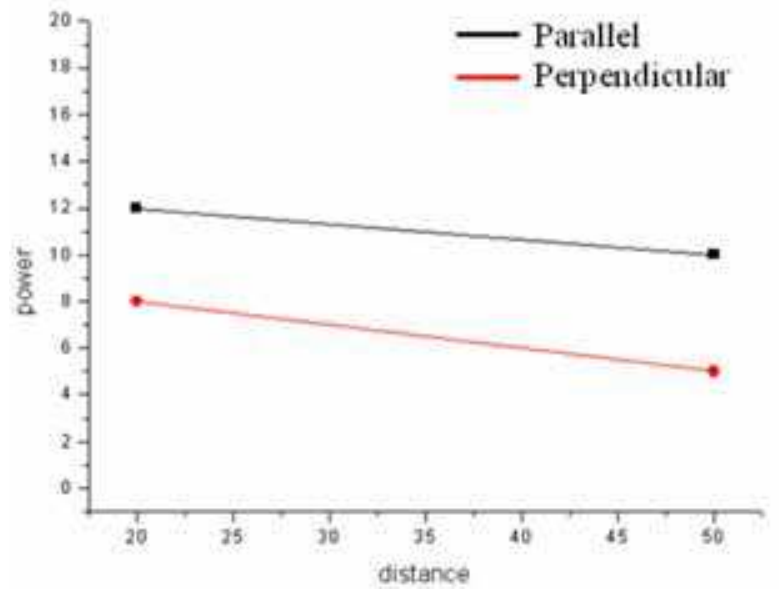

Fig. 12. Strength of the transmitted RF signal from reader antenna to tag according to the angle between them

However, the tag is attached inside of the coil then the RF signal transmitted from reader antenna propagates inside of the coil, which works as cylinder waveguide. Since there are various RF signal propagation modes according to the size of the coil (Pozar, 2005), (Balantis, 1996), the identification performance is different from that in free space. In order to test the RF signal propagation in coil, we make model coils using sheet zinc as shown in Fig. 13. The lengths of the model coils are $90 \mathrm{~cm}$ and $180 \mathrm{~cm}$, the inner radiuses are $50.8 \mathrm{~cm}$ and $61 \mathrm{~cm}$, respectively, and reader antenna is attached to position of $15 \mathrm{~cm}$ upper from the coil center reflecting the general coil size and the position of the crane shoe. 


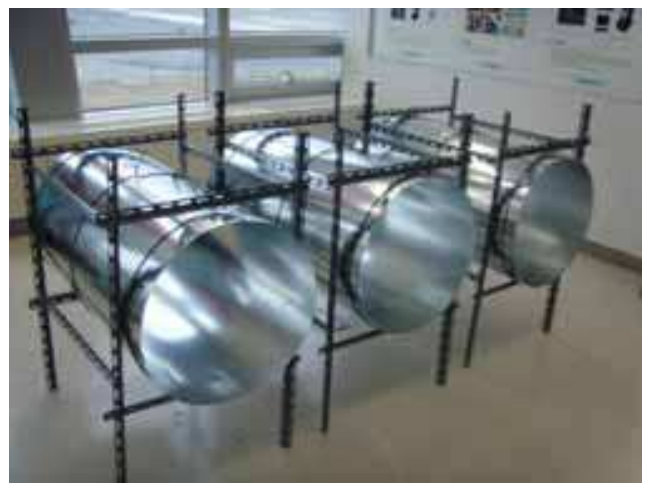

Fig. 13. Model coils used in the experiment.

The experiment conditions and the test results are shown in Fig. 14 and 15. Tag is attached to coil with the of $20 \mathrm{~cm}$ and $50 \mathrm{~cm}$ distance from the coil plane. The coordination of the graph is same with Fig. 12. When the coil radius is $61 \mathrm{~cm}$, the strength of transmitted RF signal to the tag attached perpendicular to the coil plane is weaker than the parallel as same as in free space propagation. However, with the coil of $50.8 \mathrm{~cm}$, the results are opposite. The reader can send more signal to the tag attached to the cylinder direction. It is caused by the effect of the $\mathrm{RF}$ signal propagation mode according to the coil inner radius.

The RF signal propagations in various coils are simulated using MWS $2008 \mathrm{EM}$ simulator of CST AG. in same condition of previous experiment. The simulation results are shown in Fig. 16. The reader antenna and the tag are set as port 1 and port 2 and the blue line of the graph is the S12, the transmitted signal strength from port 1 to port 2 . The initial strength of RF signal from port 1 is $30 \mathrm{dBm}$. As shown in the figure, the simulation results are same with the experimental results.

Note that the RF signal propagation in the coil is different from that in free space. The strength of the transmitted RF signal is affected by the propagation mode determined by the coil condition such as the radius of the coil. Since many kinds of coils are manufactured with various radiuses and lengths, it is impossible to make any standard for tag attachment method. However, the simulation and experimental results prove that even though the tag and reader antenna is orthogonal, tag inside a coil can be read. Based on the results, we choose the perpendicularly attachment method, because the method has more advantages such as easy to attach and with less possibility of damage.

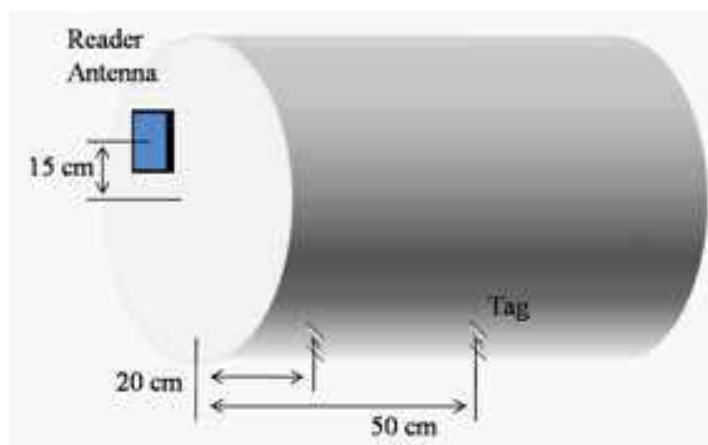

Fig. 14. The positions of tag and the reader antenna in the experiment 
Coil with radius of $61 \mathrm{~cm}$
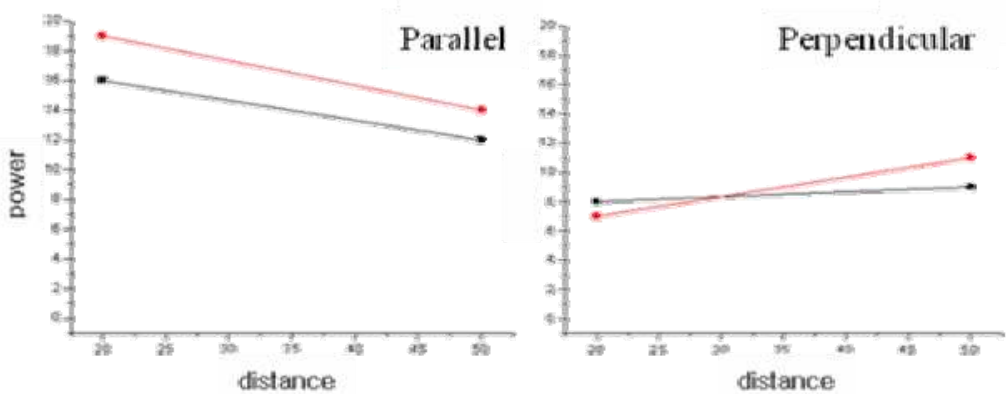

Coil with radius of $50.8 \mathrm{~cm}$
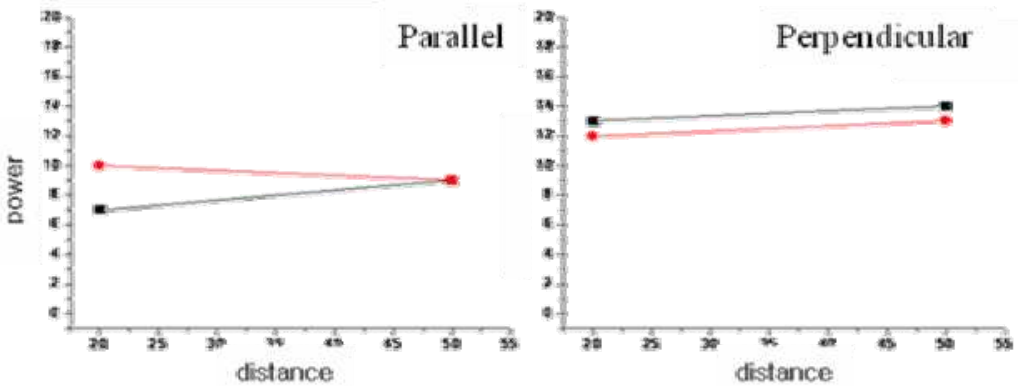

Fig. 15. Experimental results according to the tag attachment methods.

Coil Radins $50.8 \mathrm{~cm}$

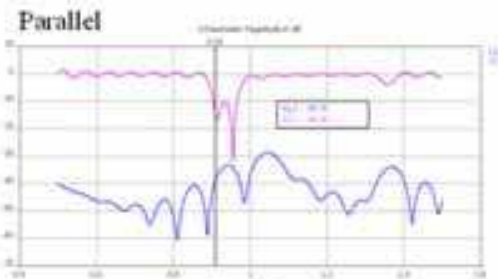

S12: $-38.78 \mathrm{~dB}$

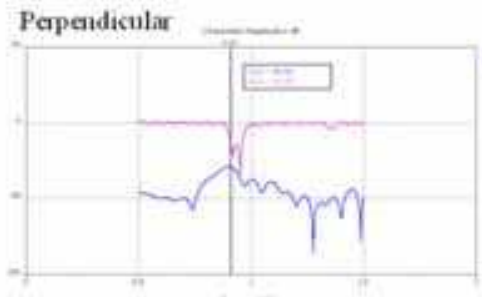

$\mathrm{S} 12-28.91 \mathrm{~dB}$
Coll Radius $61 \mathrm{~cm}$

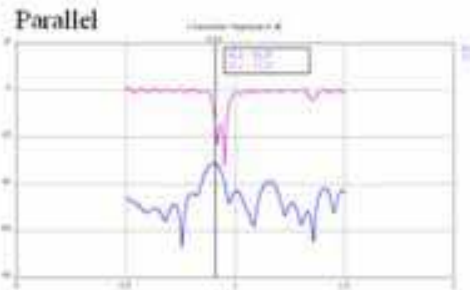

S12: $-31.37 \mathrm{~dB}$

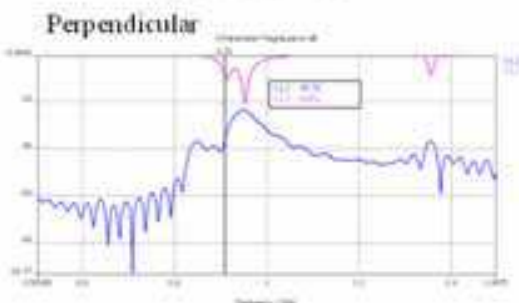

$\mathrm{S} 12-35,78 \mathrm{~dB}$

Fig. 16. Simulation results with same condition of fig. 15 


\subsection{Improvement of reader antenna}

The above results show that there is limitation to improve tag identification performance by tag attachment method. When a RF signal is propagated in waveguide, there are weak and strong points of RF signal in the guide. Fig. 17 shows the RF signal propagation pattern in the coil simulated by MWS $2008 \mathrm{EM}$ simulator. The signal is propagated irregularly and the weak and strong points are shown in the pattern. Also, there is radiation to back and side direction from the antenna. The radiation causes wrong detection of neighboring tags.

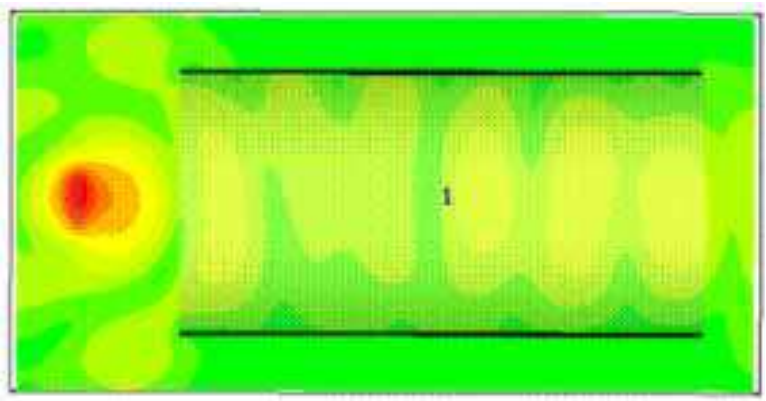

Fig. 17. RF signal propagation pattern in the coil

In the waveguide model, the reader antenna works as ports providing RF signal. Thus, the $\mathrm{RF}$ signal propagation pattern can be changed by controlling the $\mathrm{RF}$ signal radiation pattern from the reader antenna. The radiation pattern is controlled in two directions. First of all, the epi-radiation is restraint not to detect the wrong tags. Second, the beam-width should be widened as much as possible to keep the identification performance to the target tag with the high front to back ratio.

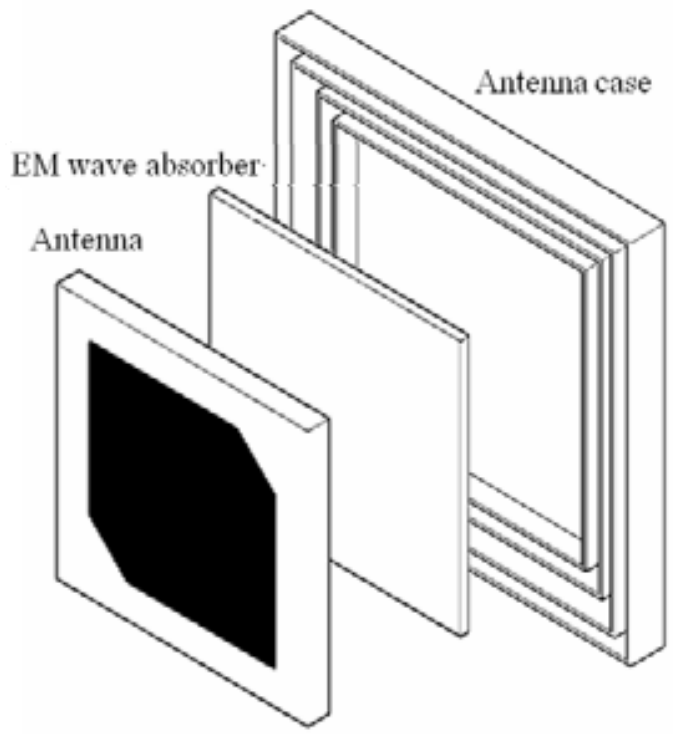

Fig. 18. Developed antenna case 
Current available space for the reader antenna at crane shoe is $\square 120 \times 20 \mathrm{~mm}$. Since the antenna should be small with enough durability to stand in the tough industrial environment, the ceramic path antenna is almost best solution. Thus, it is hard to improve the antenna.

For the problem, the antenna packaging technique is developed in this paper to control the beam pattern. Fig. 18 shows the antenna case design. The case is made using SUS (Steel Us Stainless) plate of $1 \mathrm{~mm}$. The package is metal then the antenna is not affected by the material of the attached surface. The size of the case is $\square 110 \times 20 \mathrm{~mm}$ considering the available space in crane shoe.

When an antenna is close to metallic surface, the RF signal is diffracted following the metallic surface. This diffraction causes the radiation of RF signal to side and back direction. In order to reduce the diffraction, corrugated lines are inserted between antenna and the case. The corrugated line is generally used in horn antenna (Balantis, 1996) (Mentzer \& Peters $\mathbb{R}, 1976$ ) (Pozar, 2005), by which the diffracted RF signal following the metallic surface is canceled. The $\mathrm{RF}$ signal enters and come out from slots then weaken by canceling each other as shown in Fig. 19. Also, electromagnetic wave absorber is inserted between the antenna and the case to prevent the RF signal from flowing follows the metallic surface of the case.

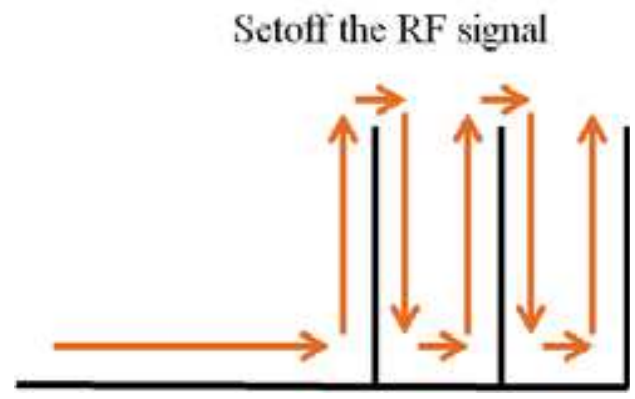

Fig. 19. RF signal is setoff by corrugated lines

To verify the validity of the proposed antenna packaging, the $\mathrm{RF}$ signal radiation pattern is simulated using MWS 2008 EM simulator. Fig. 20 shows the simulation results. The radiation pattern of a ceramic patch antenna, which is packaged in the case attached to crane shoe, is simulated. Upper figures shows the antenna model packaged in case and attached to crane shoe and 3 dimensional radiation pattern, lower graphs shows the 2 dimensional pattern. The inner green line shows the radiation pattern without case and red is with case. As shown in the figure, the beamwidth becomes wider and the epi-radiation decreases. It is expected that the identification performance will be improved with the developed case, specially, decrease of the wrong neighboring tags detection.

Fig. 21 shows the simulation results of RF signal propagation pattern in metallic coil with the case. The RF sginal regulary propagated in the coil with the proposed case. Also, the epiradiation is almost disapeard.

Based on the simulation results, the antenna case is made and tested in electromagnetic dark room sized of L4.5 $\times \mathrm{W} 9 \times \mathrm{H} 4.5 \mathrm{~m}$. Fig. 22 shows the electromagnetic dark room. In order to test more exactly, the model crane shoe is made using sheet zinc and the antenna packaged in the developed case is attached to the shoe. 

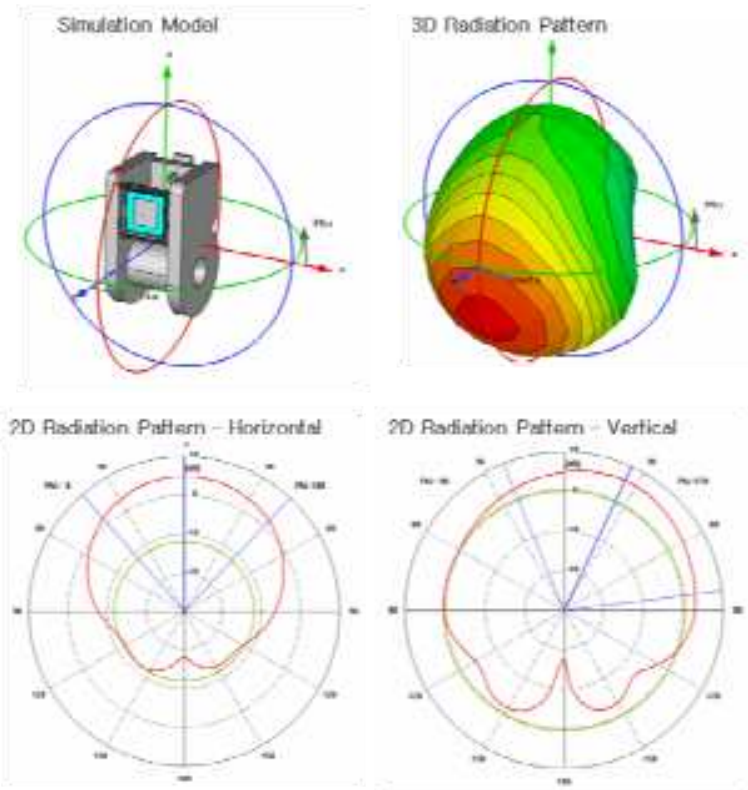

Fig. 20. $R F$ signal radiation pattern varies according to the case existence

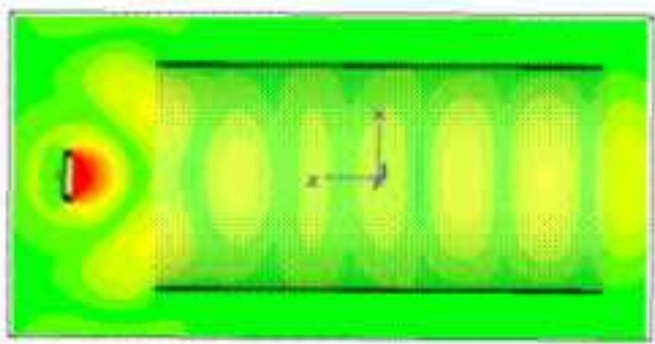

Fig. 21. RF signal propagation pattern in the coil when the case is exploited

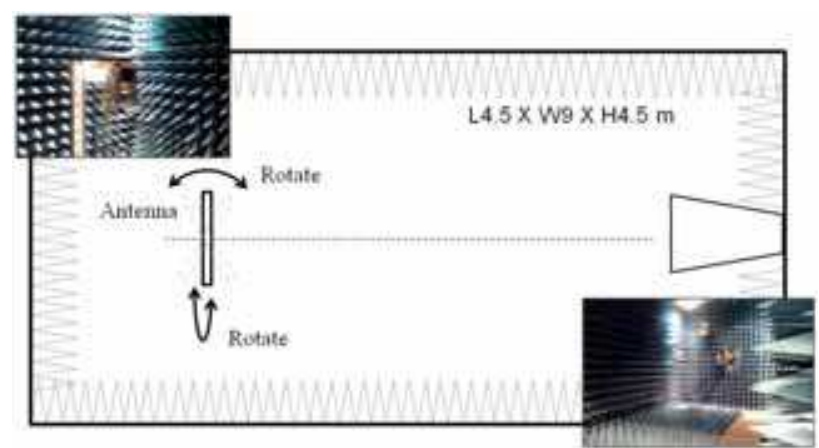

Fig. 22. (upper) overview of the electromagnetic darkroom (lower-left) antenna to be tested (low er-right) antenna to radiate $\mathrm{RF}$ signal 
Fig. 23 shows the experimental results. The upper graph shows the results without antenna case and lower graph with case. And table 4 shows the measured data such as gain, beam width, and front-to-back ratio. As shown in the figure and table, the gains with case are better than without the case. However, the beamwidth becomes narrow with the case. It is caused by canceling the RF signal flows through metallic surface in the corrugated line of the case. However, the front-to-back ratio is dramatically improved, which reduces the wrong tags detection.
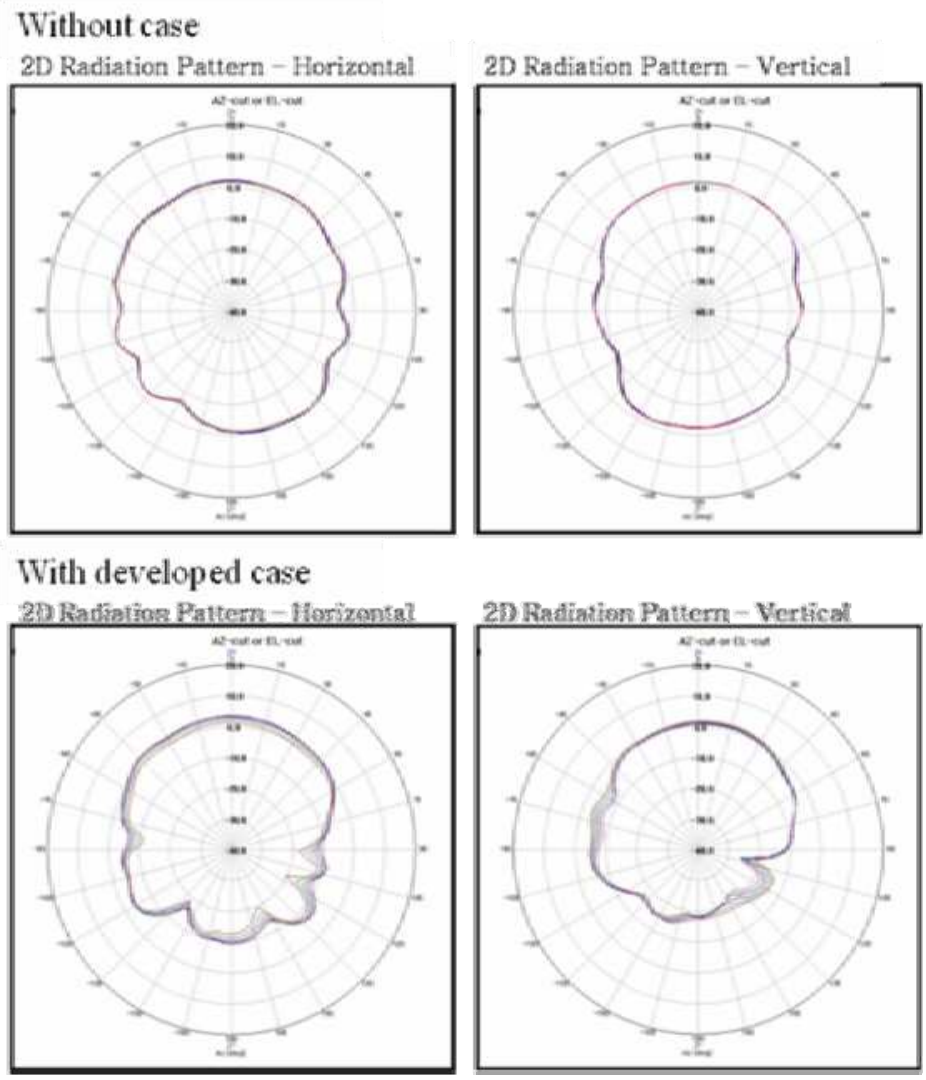

Fig. 23. (upper) Radiation pattern with case, (lower) without case

\begin{tabular}{|c|c|c|c|c|c|c|}
\hline \multirow{2}{*}{ Property } & \multicolumn{2}{|c|}{ Gain(dBi) } & \multicolumn{2}{c|}{ Bandwidth(ged.) } & \multicolumn{2}{c|}{$\begin{array}{c}\text { Front-to-Back Ratio } \\
\text { (dB) }\end{array}$} \\
\cline { 2 - 7 } & horizontal & vertical & horizontal & vertical & horizontal & vertical \\
\hline Without case & 2.10 & 1.48 & $\mathbf{1 3 1 . 8 1}$ & $\mathbf{1 0 4 . 5 9}$ & 1.66 & 3.49 \\
\hline With case & $\mathbf{3 . 9 8}$ & $\mathbf{1 . 4 9}$ & 110.39 & 94.99 & $\mathbf{1 3 . 3 1}$ & $\mathbf{1 6 . 2 9}$ \\
\hline
\end{tabular}

Table 4. Experimental results about RF signal radiation with / without case 


\section{Experiment results}

To verify the validity of the developed system, the tag identification is tested using model cylinder coil. Two more coils with tags are positioned to check the effect of the neighboring coils and tags as shown in Fig. 24. The tag is attached inside in the coil head to the same direction of the cylinder with $50 \mathrm{~cm}$ distance from the coil plane. In order to whole range inside of the coil, the tag is attached from top of coil to bottom with an interval of 30 degrees in clockwise. The distances between coils are determined reflecting the position relation of stored coils in POSCO. The test results are shown in table 5. The tag position of 0 degree is the top of the coil. The sign of $\square$ means that the wrong neighboring tags are detected, $\times$ the target tag is not detected. As shown in the table, the target tag are successfully identified with the antenna packaged in the developed case. Even though there are neighboring tags near from the antenna, the reader can detect target tag only.

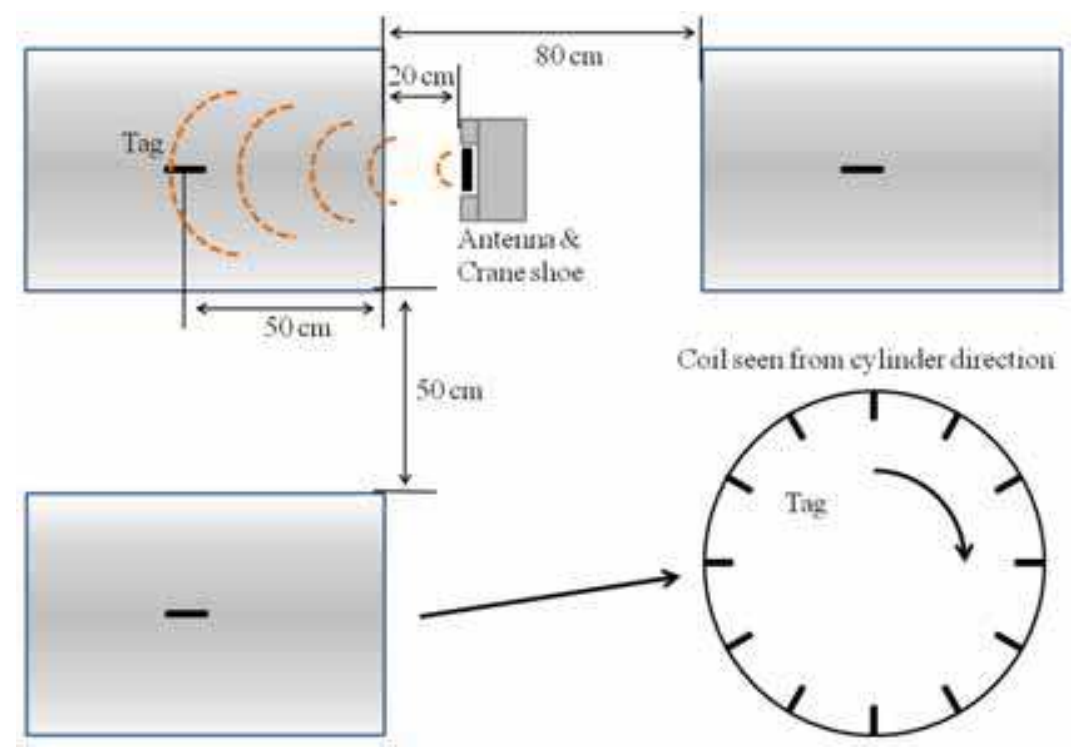

Fig. 24. Condition of experiment

\begin{tabular}{|c|c|c|c|c|c|c|c|c|c|c|c|c|}
\hline $\begin{array}{c}\text { Tag position } \\
\text { (Degree) }\end{array}$ & 0 & 30 & 60 & 90 & 120 & 150 & 180 & 210 & 240 & 270 & 300 & 330 \\
\hline $\begin{array}{c}\text { Without } \\
\text { Case }\end{array}$ & $\circ$ & $\times$ & $\bigcirc$ & $\bigcirc$ & $\times \square$ & $\bigcirc$ & $\bigcirc$ & $\square$ & $\times$ & $\bigcirc$ & $\bigcirc$ & $\circ$ \\
\hline With Case & $\bigcirc$ & $\bigcirc$ & $\bigcirc$ & $\bigcirc$ & $\bigcirc$ & $\bigcirc$ & $\bigcirc$ & $\bigcirc$ & $\bigcirc$ & $\bigcirc$ & $\bigcirc$ & $\circ$ \\
\hline
\end{tabular}

Table 5. Experimental results of tag identification performance with / without case

Table 6 shows the experiment results in POSCO. The test is performed during two days, because enough tags to test the interference are already in the warehouse stored at previous test. The number in the parenthesis is the number of detected tag that is attached in previous test. The direction is parallel to the coil plane. As shown in the table, the error rate is dramatically decreases under the $0.5 \%$. The results satisfy the success rate of $99 \%$ that is required in the industrial filed then the system can be applied in the coil identification. 


\begin{tabular}{|c|c|c|c|}
\hline \multicolumn{2}{|c|}{ Day } & 1st & 2nd \\
\hline No. of Manufactured Coils with tag & 405 & 392 \\
\hline \multirow{3}{*}{ Error } & $\begin{array}{c}\text { Identify wrong } \\
\text { coil }\end{array}$ & $2(1)$ & $0(1)$ \\
\cline { 2 - 4 } & Missing & 0 & 0 \\
\hline \multicolumn{2}{|c|}{ Error rate (\%) } & $0.49(0.25)$ & $0(0.26)$ \\
\hline
\end{tabular}

Table 6. Experimental results in real environment

\section{Conclusions}

This paper describes RFID based metal products identification technique for SCM of iron and steel industry. Specially, the coil identification system is developed. To cope with the falling off the tag identification performance affected by neighbouring metallic objects, the tag attachment method based on flagtag is proposed and the reader antenna packaging technique is developed to improve the performance of target coil identification. A Crane equipped with the developed system can detect the tag attached inside a target coil very successfully. Our main contributions can be summarized as: 1) The RFID based products identification system is developed for iron and steel industry, which is most difficult field to apply RFID. Thus, the system can be widely spread in other industrial fields. 2) The coil identification system during the process of manufacturing, storing, and shipping by crane is developed. Since the system is for managing the products information automatically, it can contribute the SCM in steel and iron environment. The future efforts includes the improvement of the developed system to cover another products such as steel plates and spreading the RFID technology to whole SCM systems that requires the products identification.

\section{References}

B. Victor, M. Otsuka, S. Stefan, T, Kumbayashi, H. Klaus (2006), A method for applying a RFID tag carrying label on an object, US patent, WO/ 2006/ 045395.

C. A. Balantis (1996), Antenna Theory: Analysis and Design, Wiley Text Books, ISBN-10: 9971512335.

C. A. Mentzer, L. Peters $\mathbb{R}(1976)$., Pattern Analysis of Corrugated Horn Antenna, IEEE Transaction on antennas and propagation, Vol.24 No. 3.

D. M. Pozar (2005), Microwawe Engineering $3 / E$, Jhn Wiley \& Sons, INC. ISBN10:0471448788, Canada

J. Landt(2001), Shrouds of Time: The History of RFID

K. Finkenzeller (2003), RFID Handbook: Fundamentals and Applications in Contactless Smart Cards and Identification, John Wiley \& Sons Ltd., ISBN-10: 0470955038, Canada.

P. V. NIikitin and K. V. S. Rao(2006), Theory and Measurement of Backscattering from RFID Tags, IEEE Antenna and Propagation Magazine, Vol. 48, No. 6.

S.-J. Kim, B.-K Yu, H.-J Lee, M.-J. Park, F.J. Harackiewicz, and B.-J Lee (2005), RFID tag antenna mountable on metallic plates, Asia Pacific Microwave Conference, Vol. 4, ISBN: 0-7803-9433-X.

V. Chawla and D. S. Ha (2007), An Overview of Passive RFID, Communication Magazine, Vol. 45 , pp. $11-17$, ISSN: $0163 * 6804$.

W. L. Stutzman and G. A. Thiele (1999), Antenna Theory and Design, John Wiley \& Sons Ltd., ISBN-10: 0471025909, Canada. 


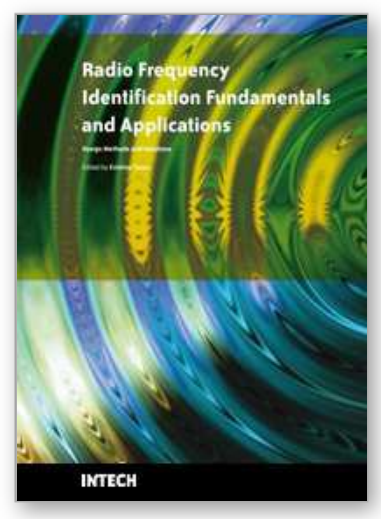

\author{
Radio Frequency Identification Fundamentals and Applications \\ Design Methods and Solutions \\ Edited by Cristina Turcu
}

ISBN 978-953-7619-72-5

Hard cover, 324 pages

Publisher InTech

Published online 01, February, 2010

Published in print edition February, 2010

This book, entitled Radio Frequency Identification Fundamentals and Applications, Bringing Research to Practice, bridges the gap between theory and practice and brings together a variety of research results and practical solutions in the field of RFID. The book is a rich collection of articles written by people from all over the world: teachers, researchers, engineers, and technical people with strong background in the RFID area. Developed as a source of information on RFID technology, the book addresses a wide audience including designers for RFID systems, researchers, students and anyone who would like to learn about this field. At this point I would like to express my thanks to all scientists who were kind enough to contribute to the success of this project by presenting numerous technical studies and research results. However, we couldn't have published this book without the effort of InTech team. I wish to extend my most sincere gratitude to InTech publishing house for continuing to publish new, interesting and valuable books for all of us.

\title{
How to reference
}

In order to correctly reference this scholarly work, feel free to copy and paste the following:

Myunsik Kim, Beobsung Song, Daegeun Ju, Eunjung Choi, and Byunglok Cho (2010). Development of Metallic Coil Identification System Based on RFID, Radio Frequency Identification Fundamentals and Applications Design Methods and Solutions, Cristina Turcu (Ed.), ISBN: 978-953-7619-72-5, InTech, Available from: http://www.intechopen.com/books/radio-frequency-identification-fundamentals-and-applications-designmethods-and-solutions/development-of-metallic-coil-identification-system-based-on-rfid

\section{INTECH}

open science | open minds

\section{InTech Europe}

University Campus STeP Ri

Slavka Krautzeka 83/A

51000 Rijeka, Croatia

Phone: +385 (51) 770447

Fax: +385 (51) 686166

www.intechopen.com

\section{InTech China}

Unit 405, Office Block, Hotel Equatorial Shanghai

No.65, Yan An Road (West), Shanghai, 200040, China

中国上海市延安西路65号上海国际贵都大饭店办公楼 405 单元

Phone: +86-21-62489820

Fax: $+86-21-62489821$ 
(C) 2010 The Author(s). Licensee IntechOpen. This chapter is distributed under the terms of the Creative Commons Attribution-NonCommercialShareAlike-3.0 License, which permits use, distribution and reproduction for non-commercial purposes, provided the original is properly cited and derivative works building on this content are distributed under the same license. 